\title{
Cross-sectional survey of depression and anxiety in a diabetes clinic population: levels and role in blood sugar control
}

Hammad Lakhani, Isobel Cane, Michelle Taylor, Paul Chadwick, Miranda Rosenthal Royal Free Hospital, Hampstead NHS Trust Hospital, London, UK

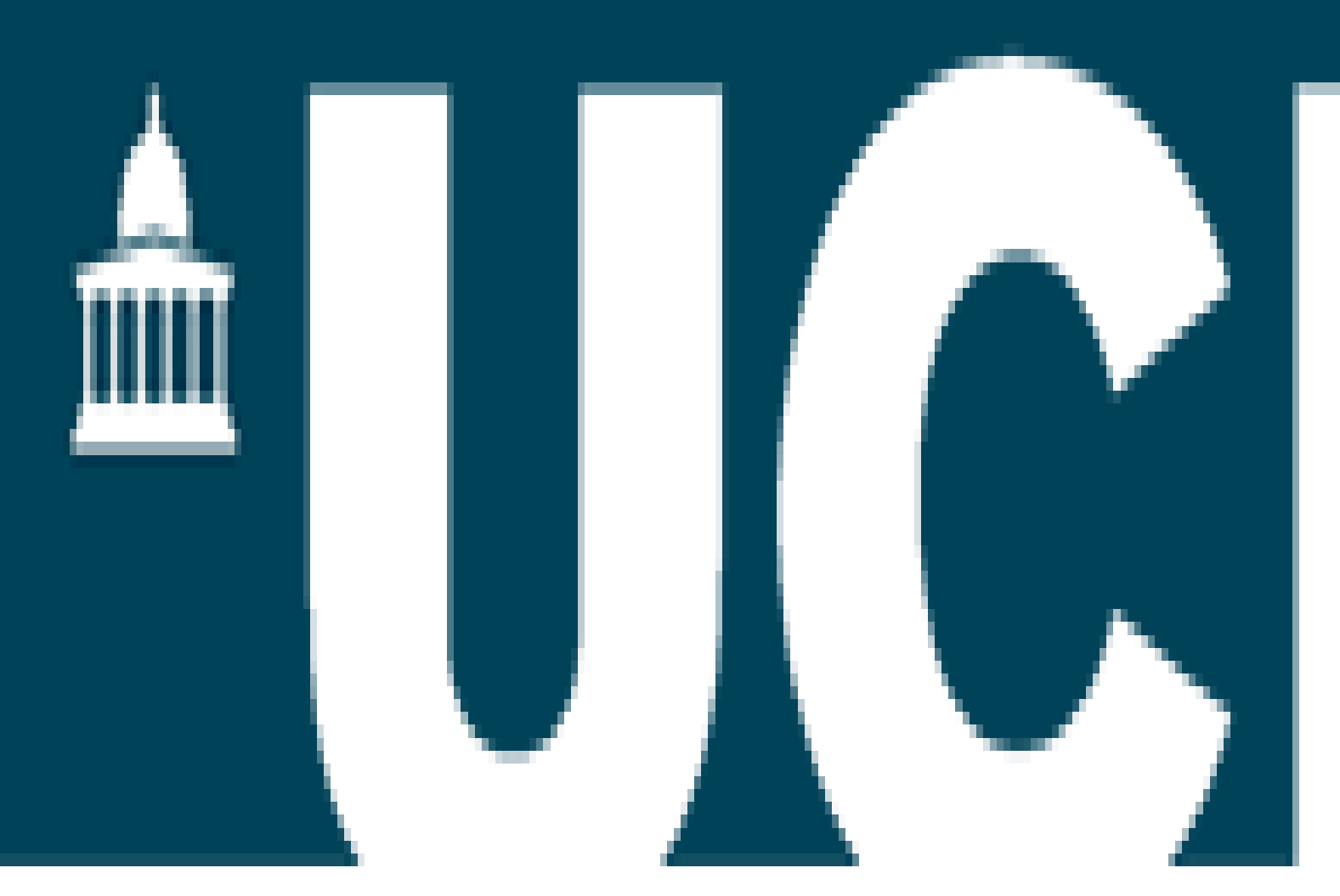

\section{Introduction}

Diabetes is a common, chronic condition which despite support from a multidisciplinary team, adds a significant burden of responsibility to the individual. As a result, many people with diabetes have poor psychological wellbeing and are twice as likely to suffer from depression as the general population (1). This is particularly important to address as studies have shown that diabetes and co-morbid depression lead to poorer clinical outcomes (2).

Furthermore, reports show that $85 \%$ of people with diabetes do not have access to specialist psychology services with fewer than $3 \%$ of diabetes services meeting the psychologically relevant NSF standards and NICE (3). The NSF standards emphasise the importance of supporting diabetics in their psychological development and in maintaining good diabetic control. It is therefore essential to identify and cater for the psychological needs of the diabetic population.

The aims of the study were to:

- To establish the prevalence of depression and anxiety within the clinic and the effects on diabetic control and clinical outcomes.

To make visible the extent and range of need for access to specialist psychology services within the clinic.

\section{Methods}

142 diabetic patients (type 1 diabetes $n=67$, type 2 diabetes $n=60$ ) attending outpatient clinic at the Royal Free Hospital gave their consent to participate. Depression and anxiety were measured using the PHQ-2 (patient health questionnaire) and the GAD-2 (general anxiety disorder) respectively. The PHQ-2 score is based on DSM-IV criteria and has a sensitivity of $89.2 \%$ and a specificity of $90 \%$ for major depression in comparison to mental health interviews by professionals. Other psychological components assessed were fear of hypoglycaemia and eating disorder.

The data was supported with questions on patient characteristics and clinical outcomes. These included items on diabetes complications and selfmanagement behaviours (i.e. home blood glucose monitoring, $\mathrm{HbA} 1 \mathrm{c}$ frequency of injections, diet and treatment satisfaction).

The data were analysed using SPSS for Windows. Comparisons of continuous variables was by T-test and categorical data was compared using the Chi-square test. Anxiety and depression were correlated using Pearson's test. A significance level of $95 \%$ was used.

\section{Conclusions}

From this data, it can be seen that there is a high prevalence of depression $(27 \%)$ and anxiety $(20 \%)$, which is more than double the population level (8$12 \%)(4)$. It is also evident that depression leads to significantly poorer selfmanagement behaviours, with increased odds of: higher number of complications, higher self reported blood glucose levels and poorer selfmonitoring of blood sugar levels. By identifying and intervening to reduce depression in this population, it is possible to improve their glucose control and therefore improve long term clinical outcomes as well as dealing with their psychological disorder.

There is also an association of depression with fear of hypoglycaemia and eating problems, which can also contribute to poorer clinical outcomes. Patients with depression also suffer from increased incidences of severe hypoglycaemia, including loss of consciousness or a fit. These can have disastrous consequences and so it is essential to treat any possible underlying causes such as depression.

$90 \%$ of the clinic population also felt that having psychological services by staff that know about their diabetes is important with the majority saying it is very important.

This gives an evidence base for a greater level of psychological service provision tailored to the patients' needs. The data also emphasises the importance for physicians to actively screen for depression.

\section{Results}

The prevalence of depression and anxiety are $27 \%$ and $20 \%$ respectively and there is a strong correlation between these variables $\left(R^{2}=0.59\right)(F i g 1)$. There are significantly increased odds of having poorer management behaviours and a higher number of complications and self reported high sugar levels in patients with depression, as well as greater prevalence of fear of hypoglycaemia (Fig 2). When asked about the importance of having a clinical psychologist who knows about their diabetes, $20 \%$ feel it is moderately important and $70 \%$ feel it is very important, whilst only $10 \%$ do not see it as important.

\begin{tabular}{|c|c|c|}
\hline & Frequency & Percentage \\
\hline Depression & 39 & 27 \\
\hline Anxiety & 29 & 20 \\
\hline \multicolumn{3}{|l|}{ Sex } \\
\hline Male & 78 & 54.5 \\
\hline Female & 62 & 43.4 \\
\hline BMI & 26.8 (S.D. = 5.8) & \\
\hline \multicolumn{3}{|l|}{ Type of diabetes } \\
\hline Type 1 & 67 & 46.9 \\
\hline Type 2 & 60 & 42 \\
\hline Other & 8 & 5.6 \\
\hline Duration of diabetes (years) & 17 (S.D. $=13$ ) & \\
\hline \multicolumn{3}{|l|}{ Insulin } \\
\hline Yes & 111 & 77.6 \\
\hline No & 26 & 18.2 \\
\hline \multicolumn{3}{|l|}{ Oral hypoglycaemic agents } \\
\hline \multicolumn{3}{|l|}{ Yes } \\
\hline 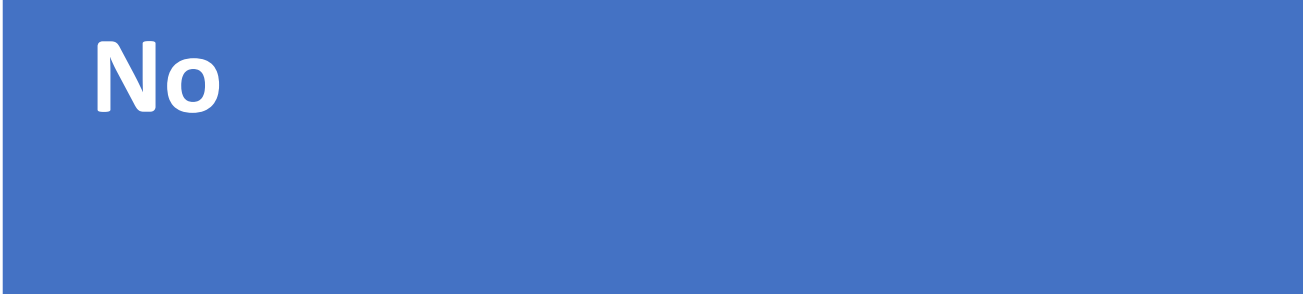 & 84 & 58.7 \\
\hline HbA1c & 69.5 (S.D. = 23) & \\
\hline
\end{tabular}

Figure 1: Patients' characteristics and prevalence of psychological disorders

\begin{tabular}{l|c|}
\hline Odds ratios & $\begin{array}{l}\text { Depression vs No } \\
\text { depression }\end{array}$ \\
\hline Self reported high bgl & 2.85 \\
\hline Poor self monitoring & 3 \\
\hline$>3$ complications & 8.7 \\
\hline Fear of hypoglycaemia & 3.4 \\
\hline $\begin{array}{l}\text { Severe episodes of hypoglycaemia } \\
\text { (daytime) }\end{array}$ & 3.2 \\
\hline $\begin{array}{l}\text { Severe episodes of hypoglycaemia } \\
\text { (night time) }\end{array}$ & 6 \\
\hline eating out of control & 2.82 \\
\hline
\end{tabular}

Figure 2: Odds ratios for depression vs no depression. Bgl = blood glucose level. Significance $P<0.05$ 